\title{
Acute Formic Acid Poisoning: A Case Series Analysis with Current Management Protocols and Review of Literature
}

\author{
${ }^{1}$ Ravishankar S Bhat, ${ }^{2}$ Sudhir M Naik, ${ }^{3} \mathrm{MK}$ Goutham, ${ }^{4} \mathrm{CR}$ Bhat, ${ }^{5}$ Mohan Appaji, ${ }^{6} \mathrm{KV}$ Chidananda \\ ${ }^{7}$ Nongthomban Pinky Devi, ${ }^{8}$ Sherry Joseph, ${ }^{9}$ Pooja Nayak
}

\begin{abstract}
Background: Formic acid (FA) being pungent, odorless, easily available and consumed for suicidal purposes and the dilute form being colorless and odorless is consumed accidentally. Accidental ingestion is rare and deliberate self-harm is very painful and violent which has been a rare modality of committing suicide but for these areas where it is easily available.

Materials and methods: This a retrospective case series analysis study 14 patients with acute formic acid poisoning. There were 14 patients, with 3 females and 11 males. The average age was 35.5 years, with the average in males being 34.9 and 37.6 in females. Thirty milliliter were considered as cutoff range as diluted/undiluted FA below $30 \mathrm{ml}$ were managed in our institution and $30 \mathrm{ml}+$ were referred to higher toxicology speciality care.
\end{abstract}

Results: Act of deliberate self-harm was seen in 11 cases (78.5\%) and accidental ingestion in three cases (21.5\%). All had orofacial burns, 4 had mild hematemesis and 3 severe hematemesis with impending renal complications. All the stabilized and referred cases were no further evaluated for follow-up. Facial burns and contracture needing cosmetic correction was seen in three cases, while corneal and lid scarring seen in two cases while a case of esophageal stricture with lower GIT and renal complications were seen in one case.

Conclusion: Formic acid poisoning is uncommon, and limited literature review is available with fewer protocols laid. So, immediate management of this corrosive poisoning with supportive measures reduces the mortality drastically. Serial upper gastrointestinal imaging diagnose stricture earlier and cosmetic reconstruction helps in facial scarring and contractures.

Keywords: Formic acid, Hematemesis, Endoscopy, Metabolic acidosis.

How to cite this article: Bhat RS, Naik SM, Goutham MK, Bhat CR, Appaji M, Chidananda KV, Devi NP, Joseph S, Nayak P.

\footnotetext{
${ }^{1}$ Associate Professor, ${ }^{2}$ Fellow, ${ }^{3}$ Assistant Professor

${ }^{4,5}$ Professor, ${ }^{6}$ Professor and Head, Director

${ }^{7-9}$ Senior Resident

1,3,5,7-9 Department of ENT, Head and Neck Surgery, KVG Medical College, Sullia, Karnataka, India

${ }^{2}$ Department of Cosmetic and Image Enhancement Surgery Cosmetic Surgery Institute, Mumbai, Maharashtra, India

${ }^{4}$ Department of General Medicine, KVG Medical College Sullia, Karnataka, India

${ }^{6}$ Department of General Surgery, KVG Medical College, Sullia Karnataka, India
}

Corresponding Author: Ravishankar S Bhat, Associate Professor, Department of ENT, Head and Neck Surgery, KVG Medical College, Sullia Karnataka, India, Phone: 9916807109 e-mail: drraveesha@gmail.com
Acute Formic Acid Poisoning: A Case Series Analysis with Current Management Protocols and Review of Literature. Int J Head Neck Surg 2014;5(3):104-107.

Source of support: Nil

Conflict of interest: None

\section{INTRODUCTION}

Natural rubber, also called India rubber is harvested mainly in the form of the latex from rubber trees (Hevea brasiliensis). ${ }^{1}$ The latex is a sticky, milky colloid drawn off by making incisions into the bark and collecting the fluid in vessels in a process called 'tapping'. ${ }^{1}$ It is then refined into rubber ready for commercial processing. ${ }^{1}$ Latex is generally processed into either latex concentrate for manufacture of dipped goods or it can be coagulated under controlled, clean conditions using formic acid (rubber acid, FA). ${ }^{1}$

So, FA is easily available and can be misused for deliberate self-harm and more commonly accidental ingestion as it is a colorless and odorless in dilute form. ${ }^{2}$ In the concentrated form being pungent and odorless it is mixed with country liquor and consumed for suicidal purposes and the dilute form being colorless and odorless is consumed accidentally. ${ }^{1,3}$ Deliberate self-harm is very painful and violent, and survivors want to erase the nightmare. Ninety percent of the cases are of suicidal intent and accidental consumption forms a lesser fraction. ${ }^{1,4}$ Accidental ingestion is rare, and deliberate self-harm is very painful and violent, which has been a rare modality of committing suicide but for these areas where it is easily available. ${ }^{1,4}$

This series analysis is an attempt at understanding the clinical scenario and identifying the predictors of fatality in acute formic acid poisoning and their successful management.

\section{MATERIALS AND METHODS}

This a retrospective case series analysis study done during the study period of 54 months from June 2009 to 2013. All the patient with history of rubber acid (FA) ingestion treated in our hospital were included in the study. All the cases admitted for other poisoning were excluded from the study. There were 14 patients, with 3 females and 11 males. The average age was 35.5 years, with the average in males being 34.9 and 37.6 in 


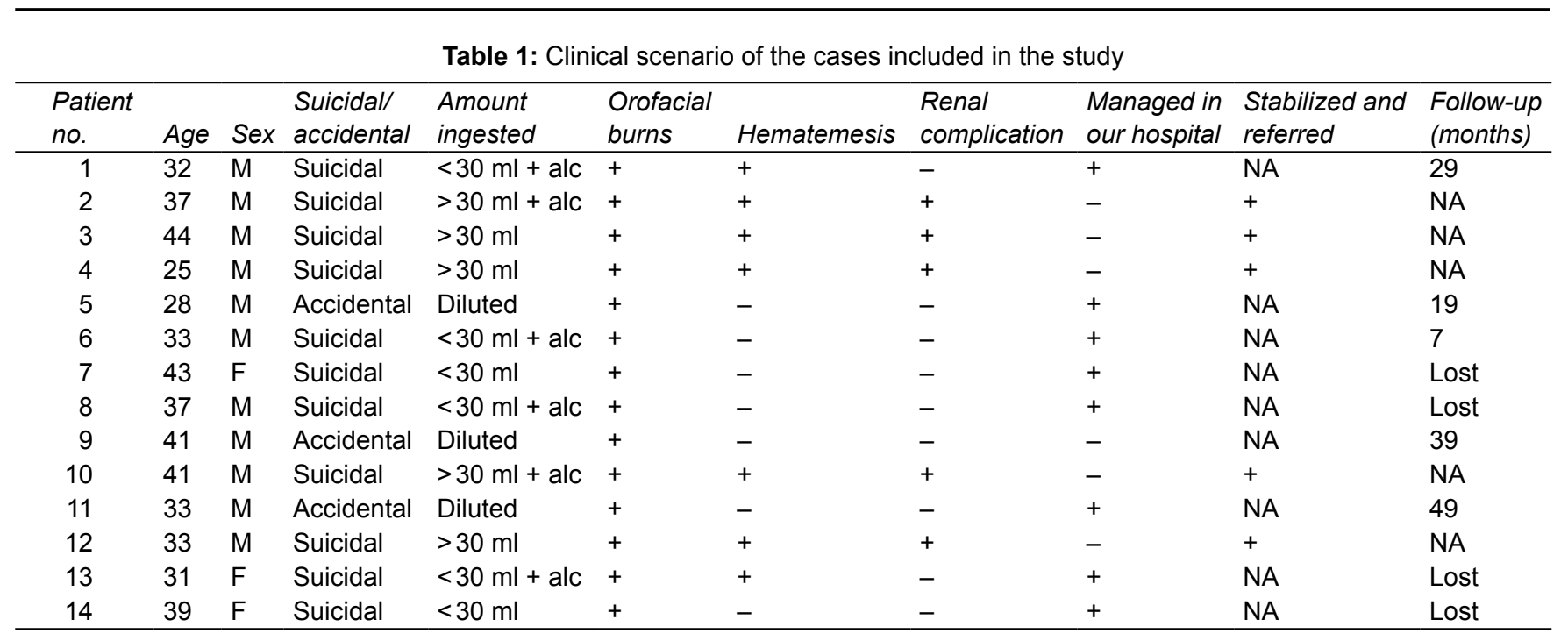

NA: Not applicable

Table 2: Two years follow-up of the cases in the study

\begin{tabular}{|c|c|c|c|c|c|}
\hline $\begin{array}{l}\text { Patient } \\
\text { no. }\end{array}$ & $\begin{array}{l}\text { Facial } \\
\text { burns/ } \\
\text { contracture }\end{array}$ & $\begin{array}{l}\text { Eye } \\
\text { injury }\end{array}$ & $\begin{array}{l}\text { Esophageal } \\
\text { stricture }\end{array}$ & $\begin{array}{l}\text { Lower } \\
\text { GIT } \\
\text { problems }\end{array}$ & $\begin{array}{l}\text { Renal } \\
\text { compli- } \\
\text { cations } \\
\end{array}$ \\
\hline 1 & + & - & - & - & - \\
\hline 2 & NA & NA & NA & NA & NA \\
\hline 3 & NA & NA & NA & NA & NA \\
\hline 4 & NA & NA & NA & NA & NA \\
\hline 5 & - & - & - & - & - \\
\hline 6 & - & - & - & - & - \\
\hline 7 & + & + & + & + & + \\
\hline 8 & - & - & - & - & - \\
\hline 9 & + & + & + & + & \\
\hline 10 & NA & NA & NA & NA & NA \\
\hline 11 & - & - & - & - & - \\
\hline 12 & NA & NA & NA & NA & NA \\
\hline 13 & - & - & - & - & - \\
\hline 14 & - & - & - & - & - \\
\hline
\end{tabular}

NA: Not applicable

females. All were recorded as medicolegal and due grave risk and the possibilities were explained (Table 1).

Immediate intensive care was established to care for airway, breathing and circulation in the medical ICU settings. A rough estimate of the consumed acid was enquired by a standard $30 \mathrm{ml}$ tea cup which is often used by the local population. Thirty milliliter were considered as cutoff range as diluted/undiluted FA below $30 \mathrm{ml}$ were managed in our institution and $30 \mathrm{ml}+$ were referred to higher toxicology specialty care (Table 2).

\section{RESULTS}

Act of deliberate self-harm was seen in 11 cases (78.5\%) and accidental ingestion in three cases (21.5\%). Six cases consumed it with alcohol, and all the accidental cases mistook the dilute ones for water. All had orofacial burns, 4 had mild hematemesis and 3 severe hematemesis with impending renal complications (Figs 1 and 2). All the stabilized and referred cases were no further evaluated for follow-up. Facial burns and contracture needing cosmetic correction was seen in three cases, while corneal and lid scarring seen in two cases, while a case of esophageal stricture with lower GIT and renal complications were seen in one case (Fig. 3).

\section{DISCUSSION}

Formic acid reaches the systemic circulation by ingestion, inhalation or absorbed through the skin. ${ }^{5,6}$ Concentrated forms are more corrosive and the dilute forms are severe eye, skin and respiratory mucosa irritants. ${ }^{5,6}$

Most of the victims are males in the 4 th to 5 th decades. ${ }^{5,6}$ Formic acid is a colorless liquid with pungent penetrating odor with the fatal dose being 50 to $200 \mathrm{ml}^{1,5,6}$

Clinical features depend on the quantity of ingestion and usually present with vomiting, respiratory distress, hematemesis and hematuria. ${ }^{7}$ Hematochezia and blood vomitus may be seen with 30 to $4 \mathrm{ml} \mathrm{FA}$ ingestion associated with acute abdomen and dark red urine. ${ }^{7,8}$ Common complaints were oral cavity burns, metabolic acidosis, septicemia, dysphagia, esophageal stricture, gastrointestinal perforation, aspiration pneumonia, ARDS, acute renal failure, chemical pneumonitis and shock. ${ }^{7,8}$

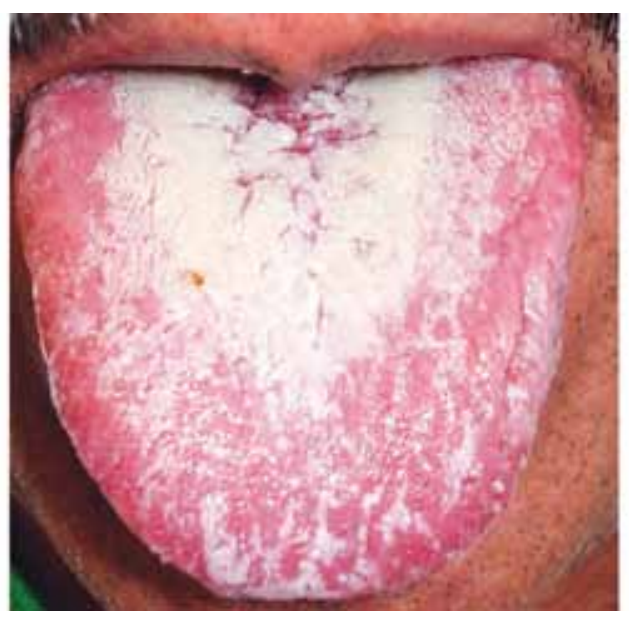

Fig. 1: Oral tongue burns 3 days after consumption 


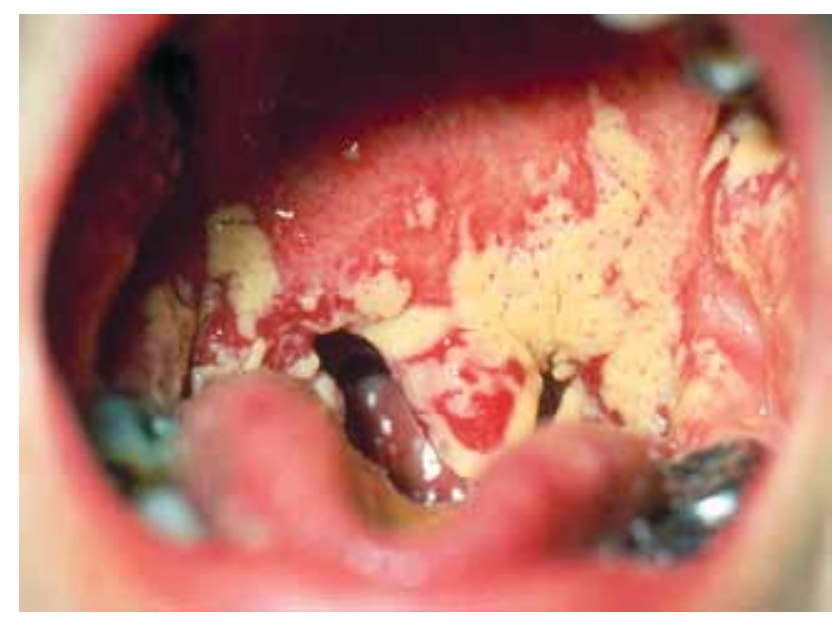

Fig. 2: Sloughing and ulceration at the palatal and posterior pharyngeal wall

Skin contacts cause erythema, blisters and severe skin burns, while corneal injuries cause clouding and loss of vision. ${ }^{7-10}$ Inhalation of the vapor can cause respiratory distress syndrome, aspiration pneumonitis and shock lung. ${ }^{11,12}$ Adult respiratory distress syndrome caused by inhalation pneumonitis manifests as cough, dyspnea, cyanosis and respiratory failure. ${ }^{11,12}$ This insoluble toxic liquid intensifies the respiratory failure and may need ventilatory support after 3 to 4 days. ${ }^{12,13}$

On ingestion burning pain, excessive salivation, intense vomiting, mucosal corrosion and ulceration is seen in the oral mucosa while upper gut ulcerations manifests as hematemesis. ${ }^{78}$ Its absorbed readily from the gut mucosa, but the coagulative necrosis may lead onto perforation. ${ }^{78}$ Rare complications were tracheoesophageal fistula and pneumomediastinum can occur. ${ }^{7,8}$ At the cellular level, it has inhibitory action on aerobic glycolysis with derailment of ATP synthesis. ${ }^{7,8}$ Hemolysis and, in severe cases, disseminated intravascular coagulation can be seen. ${ }^{7,8}$ These are monitored by prothrombin time, thombin time, serum fibrinogen, platelet counts and serum fibrinogen degradation products. ${ }^{7,8}$
The emergency management is securing the airway and maintaining the hemodynamics as the treatment is totally supportive with no specific antidote for the poisoning. ${ }^{14} \mathrm{~A}$ faster general assessment was done and persons in shock and collapsing saturation intubation with ventilator support is used..$^{15}$ It can also present with bad coma scales like drowsiness, weakness all over the body, with pupils completely dilated where immediate advanced life support is needed. ${ }^{7,8}$ Electrocardiogram (ECG) and pressures may show tachycardia or bradycardia, hypertension or hypotension, so a central monitoring is advised. ${ }^{7,8}$ Cardiovascular changes are nonspecific, both brady- and tachy-arrhythmias being observed, frequently accompanied by profound vascular hypotension. ${ }^{3,7,8}$

No oral feeds till it is established that the gastrointestinal has not occurred. ${ }^{14}$ Fluid balance with invasive acid base analysis is very accurate with intensivist care. ${ }^{14}$ Renal function is to be maintained and the empirical antibiotics are to be administered. ${ }^{14}$ Titrated doses of steroids help in stress-related imbalance but may aggravate gut mucosal hemorrhages in higher doses. ${ }^{14}$ Opoids and low dose diazepam provide analgesia after gastrointestinal hemorrhage, metabolic acidosis and renal failure are settled. ${ }^{16}$ Topical application of local anesthetics helps in pain relief and early alimentation. ${ }^{16}$

Metabolic acidosis can be managed with sodium bicarbonate intravenously tide off the mortality significantly before shifting to the intensive care setup. ${ }^{4}$ Careful follow-up with OGD is required in patients who survived with severe hematemesis or melena to diagnose early strictures. ${ }^{4}$ Instinct to induce vomiting, gastric lavage and activated charcoal should be terminated.$^{17}$ Rarely, folinic acid $(1 \mathrm{mg} / \mathrm{kg}$ IV bolus followed by 6 doses of $1 \mathrm{mg} / \mathrm{kg}$ IV doses at 4th hourly intervals) may be needed in severe systemic poisoning by enhancing formate degradation in the liver. ${ }^{18}$ Hemodialysis is useful in intractable
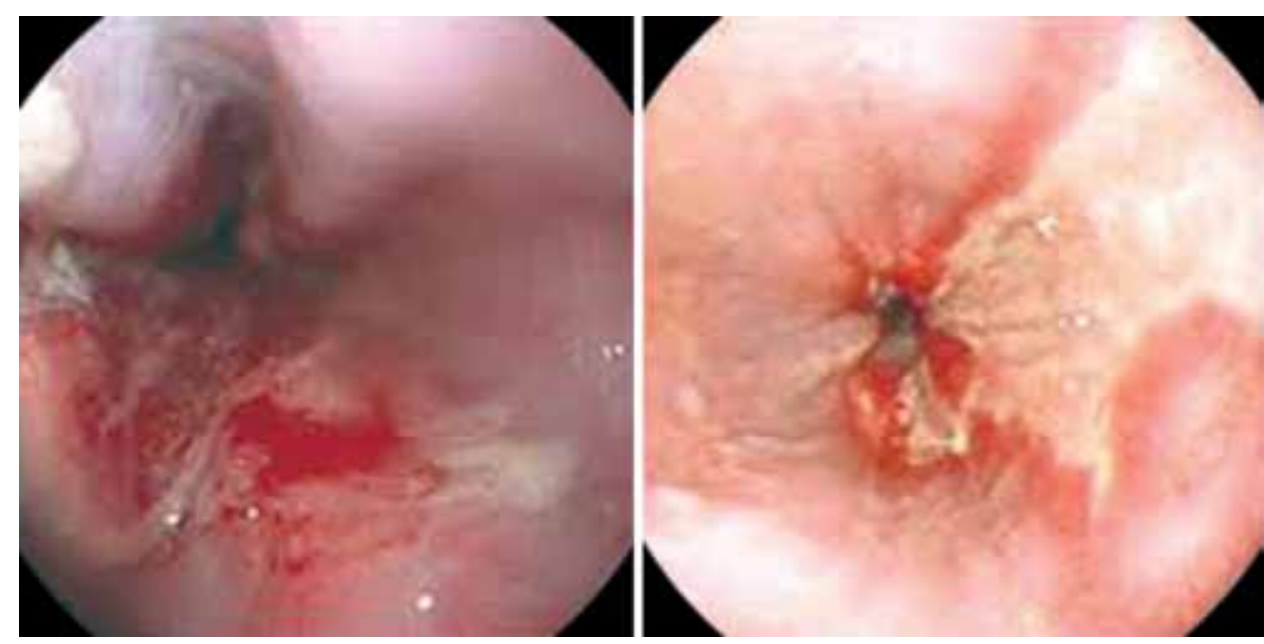

Fig. 3: Upper GI endoscopy showing the burns in esophagus 
electrolyte imbalance while exchange transfusion helps in severe intravascular hemolysis. ${ }^{3,18}$ It also helps correcting the renal failure maintaining the raising serum creatinine levels, urine output and serum potassium levels. ${ }^{19}$ Hematuria appears faster and is a poor indicator of renal function. ${ }^{19}$

Whole blood transfusions may be needed in severe hemolysis as exchange transfusions. ${ }^{15}$ Metabolic acidosis, with severe electrolyte imbalances may be evident and fatal in severe damage to the gastric wall with perforation. ${ }^{15}$ Skin burns later lead onto contractures and keloid formation on the affected area, also esophageal stricture may need a endoscopic assessment later. ${ }^{14}$

Rajan et al, reported 15 deaths due to FA poisoning where 6 had severe vascular hypotension and respiratory arrest, 4 died of acute renal failure and 5 failed to recover from gastrointestinal hemorrhage. ${ }^{1}$ They also reported orally $10 \mathrm{ml}$ proved fatal, death occurring in hours, in spite of aggressive management while 15 proved immediate fatality. ${ }^{1}$ Older patients, with severe hematemesis and uncontrolled metabolic acidosis are independent predictors of morbidity. ${ }^{1}$ Esophageal strictures may need surgical corrections while facial scars may need cosmetic and reconstructive rehabilitation. ${ }^{1}$

Mathew et al in their study of 302 cases of FA ingestion found respiratory distress in 44\%, metabolic acidosis in $70.2 \%$, ARDS in $33.8 \%$ and chemical pneumonitis in $25.5 \%$ of cases. ${ }^{20,21}$ Here, respiratory distress is significantly associated with morbidity even in cases of ingestion and many cases of mortality on autopsy showed widespread pneumonitis. ${ }^{20,21}$

Cases have been reported with mere facial skin contact of FA causing death in 6 hours. ${ }^{22}$

\section{CONCLUSION}

Formic acid poisoning is uncommon, and limited literature review is available with fewer protocols laid. So, immediate management of this corrosive poisoning with supportive measures reduces the mortality drastically. Serial upper gastrointestinal imaging diagnose stricture earlier and cosmetic reconstruction helps in facial scarring and contractures.

\section{REFERENCES}

1. Rajan N, Rahim R, Kumar SK. Formic acid poisoning with suicidal intent: a report of 53 cases. Postgrad Med J 1985 Jan;61(711): 35-36.

2. Dalus D, Mathew AJ, Pillai SS. Formic acid poisoning in a tertiary care center in south india: a 2-year retrospective analysis of clinical profile and predictors of mortality. J Emerg Med 2013;44(2):373-380.
3. Malizia E, Reale C, Pietropaoli P, Ritris GCD. Formic acid intoxications. Acta pharmacologica et toxicologica (Suppl) 1977;41(6):342.

4. Naik SM, Ravishankara S, Appaji MK, Goutham MK, Devi NP, Mushannavar AS, Naik SS. Acute accidental formic acid poisoning: a common problem reported in rubber plantations in sullia. Int J Head Neck Surg 2012 May;3(2):101-105.

5. United states department of labour, Occupational Safety and health Administration (OSHA), Occupational Safety and Health Guideline for Formic Acid; Washington: OSHA Publication; 2003 July.

6. Sigurdsson J, Björnsson A, Gudmundsson ST. Formic acid burn-local and systemic effects: report of a case. Burns 1983; 9(1):358-361.

7. Naik RB, Stephens WP, Wilson DJ, Walker A, Lee HA. Ingestion of formic acid-containing agents: report of three fatal cases. Postgrad Med J 1980 June;56(656):451.

8. Sujathan G, Jayapalan VK. Formic acid poisoning. J Ind Acad Foren Med 1991;13(2):29-31.

9. Theodore CC, Saralyn RW, Clark RF. Formic acid skin burns resulting in systemic toxicity. Annals of Emergency Medicine 1995;26(3):383-386.

10. Fernando Dinesh MG, Kaluarachchi CI. Death due to adult respiratory distress syndrome following assault with rubber acid: could it have been averted? Sri Lanka J Forensic Med Sci Law 2012 May;3(1).

11. More DK, Vora M, Wills V. Acute formic acid poisoning in a rubber plantation worker. Ind J Occupational and Environmental Med 2014 Jan-Apr;18(1):29-31.

12. Ram J, Sukhija J, Behera D, Gupta A. Ocular and systemic morbidity profile in mass formic acid injuries. Ophthalmic Surg Lasers Imaging 2010;41(2):123-127.

13. Bennion JR, Franzblau A. Chemical pneumonitis following household exposure to hydrofluoric acid. Am J Indust Med 1997;31(4):474-478.

14. Webb WR, Koutran P, Ecker RR, et al. An evaluation of steroids and antibiotics in corrosive burns of esophagus. Ann Thoracic Surg 1970;9(1):95-102.

15. Westphal F, Rochholz G, Ritz-Timme S, Bilzer N, Schütz HW, Kaatsch HJ. Fatal intoxication with a decalcifying agent containing formic acid. Int J Legal Med 2001 Feb;114(3):181-185.

16. Berlyne GM, Henry JJ, Hewitt V, Nilwarangkur S. Protein loss in peritoneal dialysis. Lancet 1964 Apr;1(7336):738-741.

17. Estresa A, Taylor W, Miller LJ, et al. Corrosive burns of the esophagus and stomach: a remainder for aggressive surgical approach. Ann Thoracic Surg 1986 Mar;41(3):276-283.

18. Moore DF, Bentley AM, Dawling S, Hoase AM, Henry JA. Formic acid and enhanced renal elimination in formic acid intoxication. Clinical Toxicol 1994;32(3):199-204.

19. Barceloux DG, Bond GR, Krenzelok EP, Cooper H, Vale JA. American academy of clinical toxicology ad hoc committee on the treatment guidelines for methanol poisoning. J Toxicol Clin Toxicol 2002;40(4):415-446.

20. Mathew AJ, Dalus D. Acute formic acid poisoning in south India, postcards from Beijing: annual meeting abstracts. J Med Toxicol 2010;6(3):361.

21. Jefferys DB, Wiseman HM. Formic acid poisoning. Postgrad Med J 1980;56(2):761-762.

22. Ernstgarda L, Iregrenb A, Sjögrena B, Johansona G. Acute effects of exposure to vapours of acetic acid in humans. Toxicology Letters 2006;165(3):22-30. 